\title{
A Study on the Use of the Balanced Scorecard for Strategy Implementation in a Large Brazilian Mixed Economy Company
}

\author{
Ricardo Vinícius Dias Jordão', Jorge Luís Casas Novas²
}

\begin{abstract}
The research described in this paper has analyzed the use of the balanced scorecard (BSC) as part of a management control system for implementing strategies in a large mixed economy company. The shareholder structure of the company combines traditional shareholder interests with those of the government. Based on a case study in Brazil, the research innovates on analyzing BSC use and contributions to translate a company's strategy (which requires bringing together different views) into objectives and goals aligned to the four BSC perspectives: financial, learning and growth, improvement of internal processes and customer. The results point out that: (I) BSC, when used as part of a MCS, provides effective improvement of the strategy implementation process and its diffusion across the different organizational levels; (2) in the company under analysis, the performance evaluation integrated qualitative, financial and productive dimensions; (3) BSC appeared as an important tool in strategy conception and implementation; and (4) BSC enables to translate the company's strategy into objectives and goals aligned to the financial, learning and growth, improvement of internal processes and customer perspectives.
\end{abstract}

Keywords: strategy; balanced scorecard; mixed economy company; management control system; brazil.

\footnotetext{
'Professor of the Graduate Program in Business Administration, Pedro Leopoldo Foundation (Brazil), CEFAGE-UE (Portugal) and Swiss Management Center (Switzerland). Vereador Nelson Cunha, 618/204 - Belo Horizonte/ Minas Gerais - 31353।80, Brazil. Phone: +5531 98582554. E-mail: jordaoconsultor@yahoo.com.br

${ }^{2}$ Assistant Professor at the Management Department, University of Évora and CEFAGE-UE (Portugal). Largo dos Colegiais, 3 - $7000-802$ Évora, Portugal. Phone: +35 I266740892. E-mail: jlnovas@uevora.pt
} 


\section{Introduction}

In recent years, the model known as Balanced Scorecard (BSC) contributed to help organizations to establish actions aligned to a value creating strategy (Moore, 2003). In addition, BSC contributes to meet the shareholder, employee and customer expectations, as well as to the improvement of service, internal processes, learning and innovation. Norton and Kaplan (200I), based on a study including almost 300 executives, stated that the capability to strategy execution is, probably, more important than strategy quality.

According to such authors, the problem is that strategies are changing very quickly but not the way to measure them. BSC was presented, initially, as a performance measurement system playing a central role in strategy implementation (SI) (Kaplan and Norton, 1992), evolving, later, to a strategy management system (Kaplan and Norton, 1993, 1996). In the current economic scenario, characterized by constant changes, the adequate monitoring of quantitative and qualitative data impacts on financial and operational performance of organizations, creating challenges to SI, mainly in mixed economy companies (MEC) which is distinct from the other companies by assembling resources from the State and individuals to exploit economic activities. Jones and Hubic (2006) explain that BSC eases the management of such data by systematizing them in four different perspectives.According to Kaplan and Norton (1996), the concept of performance evaluation and control proposed by the BSC tries to align the traditional financial perspective to three other ones linked to customer satisfaction, improvement of internal processes and learning and growth of employees. The literature has presented the benefits of BSC in public organizations (e.g. Nistor, 2008; Simões and Rodrigues, 20I I) and private organizations (e.g. Kaplan and Norton, 1993, 1996; Moore, 2003) or nonprofit organizations (cf. Moore, 2003).

Meanwhile, critical reviews on the literature have shown that the empirical results obtained are incoherent, leading to the formulation of critics or the absence of theorization. Besides some failures pointed out in the literature, there are research gaps on the use of such model as part of a management control system (MCS) and about the role of BSC on SI in MEC, especially in the case of emergent economies. Thus, the purpose of the research described in this article was to analyze the effects of the use of BSC as part of a MCS on SI in a large Brazilian MEC.

The theoretical and practical innovations of the study derive from the better understanding (I) of the use of MCS in organizations that need to congregate strategic interests from the State and the other shareholders; and (2) of the use of mechanisms enabling $\mathrm{SI}$ and promoting the congruence of objectives in such type of organizations (consisting in an im- portant management challenge). Such issues motivated and justify the present research.

\section{Strategy, BSC and MCS}

In the mid-80s, Johnson and Kaplan (1987) stated that the traditional accounting performance measures, facing only physical and financial indicators, were not sufficiently sensible to capture changes felt in an increasingly dynamic, mutable and intense business environment in communications and information processing.

The BSC is a model that provides some answers to the criticism from the end of the $X X$ century. The model was developed by Johnson and Kaplan (1987) and proposes a performance evaluation methodology directed to the overall organization (Kaplan and Norton, 200I). Such model came to help companies to establish actions in order to create value for the shareholder, to satisfy expectations of the remainder stakeholders, to implement strategies and to improve management services, internal processes, learning and innovation. To some authors, Kaplan and Norton's BSC is an important part of the MCS and not a strategic management system that includes partial indicators of intangible assets.

A MCS is a mechanism designed to mediate the implementation of a company's strategies. It is one of the main components of the management process (Anthony and Govindarajan, 2004), as it is the basis for plan implementation and thus for reaching both the business and stakeholders' objectives. Montgomery and Porter (199l) argue that implementing strategies is the bridge between identifying desirable objectives and reaching them effectively. According to Andrews (197I), formulating strategies is a mechanism that senior management employs to assess the company's strengths and weaknesses in the light of the companies' core competences, environmental opportunities and business risks. Prahalad and Hamel (1990) stress that core competences are competences that frequently have a wide, positive, desirable effect and are based on intellectual assets that distinguish a company from the others and lead it to a greater level of competitiveness.

Strategy has been perceived of and conceptualized in many different ways (Anthony and Govindarajan, 2004). In general, however, there is a consensus that a strategy describes the general direction that an organization makes explicit at the corporate, business and unit levels to reach its objectives. At the business level, concerns relate to the definition of the businesses that the company could develop and to distributing resources between them. At the corporate level, the strategic issues relate to the company's performance within a single activity, aiming at promoting diversification within a business or diversifying into several business units. At the 
unit level, the strategic issues are related to pursuing competitive advantage through cost or differentiation strategies. The study of control and managerial control systems (MCS) consists in the investigation of one of the most important stages in the managerial process (Anthony and Govindarajan, 2004), as it is the basis to deliver on the plans and the management and stakeholders' objectives. A control approach aligned with the intent of promoting employees' engagement in the management process (cf. Gomes and Salas, 1997) is, from a strategic perspective, a way to obtain competitive advantages, and, from an organizational perspective, a way to guide the organization and its members towards the administration's objective.

Drawing on a review of the literature on MCS from the late 1980s onwards, Gomes and Salas (1997) provide a comprehensive approach to control. This consists of a systemic approach to the company aiming to meet, as much as possible, the expectations of different stakeholders within the organization. These authors say that an MCS is aimed at promoting the companies' success through the wide engagement of people in the management process with a view to reaching both individual and business objectives. From the 1980s onwards, changes in the business environment led companies to a more open, international and dynamic context. As a result, their MCS are now supposed to add new indices to the traditional economic, financial, quality and productivity indicators. Some of these new indices are those related to organizational climate, culture, environmental factors, competitive position, managerial stakeholders' interests (cf. Gomes and Salas, 1997), and particularly customer satisfaction with products, services and processes.

The new approaches have proposed company-wide performance evaluation methodologies and an interface of formal control mechanisms with informal mechanisms to increase the potential of the decision-making processes (Cravens et al., 2004; Pitkänen and Lukka, 20I0). Some new MCS have also complemented the formal control systems with informal mechanisms to encourage people to behave in accordance with managerial expectations (Jordão, 2009). In this sense, the model proposed by BSC can be perceived as part of an MCS by integrating these perspectives both for formal and informal control, as well as due to the important role in the process of strategic implementation.

Several works focused on certain aspects of BSC and its organizational and management implications. However, the empirical investigation on BSC is still scarce and some of the premises of the model have not found support from the scientific community (Simões and Rodrigues, 20II). Some authors do not recognize the causal model between indicators and perspectives (e.g. Ittner and Larcker, 1998; Malmi, 200I); to other authors the systematized relationships ad- vocated by BSC model are logical - and not causal - relationships (e.g. Norreklit, 2000). Other authors, however, observed that the organization of indicators within the four perspectives and such relationships (even logical or intuitive) may represent benefits to the management process (e.g. Lipe and Salterio, 2002; Bryant et al., 2004). Despite criticism, it is observed that the role of BSC on SI has found support from the researcher community. Kaplan and Norton (1996) believe that BSC can translate the organizational mission and strategy in a set of measures that could serve as a basis for performance evaluation and measurement, and organizational management. BSC preconizes that success in $\mathrm{SI}$ is based on people commitment and the establishment of performance measures aligned to organization and all its stakeholders expectations. According to Kaplan and Norton (1992, 1993, 1996), the BSC helps to the diffusion of strategic plans of organizations across all levels, aiming to guide people actions towards present and future performance improvement through four different perspectives. Atikinson et al. (2000) believe that performance evaluation provides a critical link between planning, identifying objectives and developing strategies for their achievement, and control, which ensures that organizational members try to keep it on towards the achievement of such goals. They explain that BSC is an approach of performance evaluation that could support people's choice of primary and secondary measures of performance, to the understanding of their objectives and growth during such process. According to Norton and Kaplan (200I), nowadays, economy requires tools describing how to manage and measure knowledge-based intangible assets and strategies to value creation built on such assets.

The perception of the BSC as a model indicates that its implementation, once initiated, enables continuous improvements to organizations that use it over time. Kaplan and Norton (1992) pointed out that organizations can create their own BSC in order to obtain clarity and simplicity in the execution of their duties based on the experiences shared by others firms who have already applied this model. The focus on the performance measurement process puts the strategies at the core of the organization. This objective makes that with the measures introduced by the BSC it is possible to achieve improvements in strategic management globally. However, the successful implementation of such a model depends on the involvement of all stakeholders (from managers to people in operating levels) according to the goals and priorities established in strategic planning.

Expanding on the ideas of the previous study, Kaplan and Norton (1993) identified the factors that influenced the business through observations in organizations that have adopted the BSC. They observed that the application of this model depends on the emphasis given to the various measures arising from the mission, vision and organizational 
strategies. These authors consider that organizations cannot lose the focus brought by the BSC model - which consists of a simple way to understand the process of performance evaluation on an integrated view. One of the biggest benefits of the application of this model would focus on strategies (that would be the basis of the business) that can lead to superior performance and innovation, linking these strategies with the goals of senior management. Kaplan and Norton (1993) observed that the BSC is not a fixed model but rather a model that adapts to fluctuating universe of the organization. These authors concluded that it is necessary to define competitive strategies from different marketing and environments situations in which organizations are embedded. Only then, the managers could establish what measures would be taken in the process of performance evaluation, because business is directly influenced by the organization's mission, for their strategies, technology and also by culture, similar to the thought of Mendes (2002).

Mendes (2002), in his study on the BSC model implementation focus on a services logistics organization, observed that the BSC measures the past performance also plan future actions. This model allowed us to observe the growth, profitability and market share of the company. The use of the BSC collaborated in defining the mission, vision and for strategies formulation. This study has helped to highlight the scope of the model for service providers. Additionally, this author observed that managers could view the most fundamental business activities and decide based on avoiding premonitions. Similarly, Nakamura et al. (2005) showed that the strategic activities are implemented through functional strategies involving different areas of the value chain activities such as marketing, finance, human resource management, production, and research and development. They concluded that for the performance measurement system to be effective it must include different process variables of the organization.

Carvalho and Tostes (2007) stressed the need to define the positioning of the organization in line with its mission, vision and strategies, in a study done in a petrochemical industry organization that implemented the BSC. Nuintin (2007) stated that for the BSC implementation is necessary that the organization has defined its 'reason to exist', what their goals and how it would be met. The author noted that this model allows managers to identify what the causes and effects of transactions and decisions taken to achieve the expected results. He concluded that even in agribusiness with its specificities it is possible to successfully apply the BSC model.

The focus of the BSC model is the organization's strategy translating it into goals, initiatives and metrics. Its application contributes to management of the key- resources to future performance. The implementation of performance measures from the BSC perspectives happens in four steps: the first would be the translation of the organizational vision, the second concerns the communication and unity of goals, the third consists to business planning and the fourth step refers to the assessment and learning (Kaplan and Norton, 1996). Therefore, this model allows the organization to align its operational processes and management with a global and integrated long-term strategy. This makes it possible to evaluate the short-term, through the control activities, results and measure the effectiveness of decision making on the objectives established in the four perspectives of the BSC. This model understood as part of an MCS contributes to the organization consistently defines the vision and priorities. Moreover, this model could facilitate the strategic implementation and make the necessary adjustments integrating all segments with the aim of making it more competitive.

Originally designed for private companies, the BSC provides a full description of the measures required to "balance" their performance. However, there are examples in the literature (e.g. Mecklenburg County, USA) that adapted such model to the public sector by placing customer, people valuation and stakeholder satisfaction at the top of the hierarchy in order to reflect its objective of providing services. The idea was to promote accountability in a responsible way, the evaluation of results, and transparency, effectiveness and quality of decision making (Mecklenburg, 20I3). It is noteworthy that there are several reasons why the public sector could face difficulties in defining its strategic focus - such as lack of customer focus, lack in the sense of urgency to improvement and an inability to prioritize projects. Additionally, external factors from political or economic pressures often cause budget constraints without taking into account the impact of these restrictions on the mission and vision of the organization. Moreover, such pressures may stimulate the focus turns to the short-term issues at the expense of long-term strategic vision (Smith, 20I2). According to Nistor (2008), the effectiveness of BSC in public or private organizations derives from its use in all its three dimensions (as a performance measurement system, strategy management system and as a communication instrument), involving all the parties concerned in a new culture of strategy and quality awareness.

In MEC, such challenge is extended by the pressure towards financial results, demanded by the private sector, combined with quality requirements in providing services, transparency and credibility demanded by the public sector.Thus, a performance evaluation system developed for MEC must congregate technical and political aspects following a perspective to generate value for all stakeholders. Finally, the success of BSC implementation in MEC would depend on an adequate balance among short term and long term objectives, financial and nonfinancial measures, trend and occurrence indicators and, still, internal and external performance perspectives. 


\section{Research Methodology}

The research herein reported consists of a qualitative explicative case study (George and Bennett, 2005; Yin 1984). This is a method reportedly sensitive enough to capture the BSC complexity (Nuintin, 2007) and relevant to postulating new theories and models (Eisenhardt, 1989). The choice of a case study as research methodology is an attempt to understand and to analyze, in a detailed and systematic way, the process of strategy implementation in a Brazilian MEC. In the present study, the qualitative approach was a key tool to understand the relationship between strategy, BSC and MCS on Omega Company (OC) (fictitious name for confidentiality reasons). Therefore, the case study was deliberately chosen considering both the possibility of access to the companies' information and the managerial model of the company. The analysis was carried out to verify the use of the BSC in the implementation of the corporate strategy to the operational level focus on the business unit where the implementation of the BSC was in a more advanced stage, allowing a deeper and richer analysis - in the Distribution Business Unit (DBU). Among the several information sources, this study focused on in-depth, semi-structured interviews as primary sources of evidence included people of different positions and levels (Eisenhardt, 1989). The in-depth interviews were also conducted with the people responsible for the BSC concept in the DBU and to people who experience their application in everyday organization - selected building on their information potential.

The interview scripts approached the four BSC dimensions through 18 questions formulated drawing on the BSC literature. Instead of containing questions with predetermined answers, the script was used as a guideline for interactions. Before the interviews, the script was pre-tested to identify ambiguous, embarrassing, unclear, and unnecessary questions. After identifying shortcomings, the script was reformulated with the clarification of some questions and the rewriting of others. Overall, 23 interviews (totaling a ca. 9 hours of recording) were carried out from November 2010 through April 20II. They were transcribed and subsequently content analyzed. The average interview time reflected the interactions between researcher and participants, and also the respondents' roles and levels of education and information.

An induction and deduction process was carried out throughout the data analysis process (Eisenhardt, 1989; George and Bennett, 2005). Two levels of analysis were carried out building on the content analysis method. First, the analysis focused on the use of BSC and aimed at identifying the variables that seemed to correlate and should thus be grouped to provide a better understanding of the effect of BSC on strategy implementation. Second, the analysis focused on identifying shared or complementary perceptions among the individuals within hierarchical levels and then across different levels and business units. One major limitation of this study was the impossibility of generalizing the results indiscriminately, and some potential bias in both participants' reports and the authors' analysis, regardless the potentialities of the methods used and the researchers' endeavors to carry out an unbiased analysis. Aiming at internal validity and to offset potential biases, the results of the content analyses were also triangulated with other sources of evidence as a means of corroborating or refuting the information provided in the interviews (Jick, 1979). Triangulation first involved visits to the company's plant and office (non-participant observation) in order to learn the company's business specificities. It later involved the analysis of booklets and additional information found on web pages, on the target company's homepage, in instructional materials, in procedures manuals of corporate policies, in some historical documents of the company, and in magazine news (documentary analysis). The triangulation results are reported in the next section along with the content analysis, corroborating or refuting them. In addition, as a means of making some points clearer, the analyses also relied on its 2005 to $201 \mathrm{I}$ financial and performance indicators, on informal conversations with managers and employees, and on post-interview contact with interviewees (non-structured interviews and extra-interviews up to April 2012). Following the procedures suggested by Eisenhardt (1989) and George and Bennett (2005) for the analysis of qualitative data, it can be safely assumed that this study has included all possible levels of analysis in order to provide consistent and relevant insights that were both theoretically grounded and empirically sustained within the context of the research.

\section{Case Study Presentation and Analysis}

OC was founded in 1952 and is currently one of the biggest and most robust groups in Brazil's energy sector and the biggest of the electric sector in Latin America in market value: US $\$ 16$ billion. OC core businesses are the generation, the transmission and the distribution of electric energy, telecommunications, and the distribution and exploration of natural gas. The group acts in several regions in that country with a higher concentration in the Southeast region, as well as abroad. The OC's business vision to 2020 shows that the company intend to be one of the two biggest energy groups in Brazil in market value, with a relevant presence in Americas and a global leadership in terms of the sustainability of the sector. The OC group possesses more than 100 corporations, 15 consortia and a stock participation, more than 115 thousand shareholders in 44 countries with traded shares in the stock exchanges of New York, Madrid and São Paulo. In 2010, it presented an EBITDA of $R \$ 4,543$ billion and a net profit of $R \$ 2,257$ billion $-5,8 \%$ higher 
than $R \$ 2,133$ billion earned in 2009. Still in 20II, the net profit reached $R \$ 2,4$ billion. Data available at the site of the organization show that its strategy aims to maximize value to the shareholders, in a sustainable manner, taking into account the Master Plan (MP) from 2005 up to 2035.

The OC strategy execution becomes effective through the investment in international projects and enlargement of the action area of the group in electric power and gas distribution businesses throughout the national territory, obeying to regulatory limits of the sector. Some of the mechanisms used for expansion consist in the formation of consortia for the construction of power plants and of interests in ventures where it operates. Besides business expansion, that MEC aims to add value to the shareholders as primary objectives and to the stakeholders as secondary objectives, as preconized by Atkinson et al. (2000). Such objectives would be reached by value creation for the community through an appealing dividend policy, social and environmental responsibility, adequate business profitability, integrated risk management, improvement in operational efficiency and an agreeable workplace climate. In OC, the BSC is a model of recognized importance as it allows following the performance of financial and nonfinancial factors that contribute to the achievement of organizational strategic objectives. Such follow-up is part of a model of strategy management based on the structured flow of meetings enabling greater alignment and focus, turning continuous the planning process and strategy management.

Such model enables a structured strategic planning and timely adjustments through a system of strategic alerts that can be activated in case of necessity or opportunity, in which the senior administration is the focus and the main user of the model - operating, if necessary, any company area. The organization uses the BSC to carry out the organizational management, collaborating to Sl. The superintendent of strategic planning explains that the implementation of this model in OC has involved the following steps: (i) mobilization of executive management, (ii) construction of corporate BSC, (iii) operation of BSC through indicators, targets and initiatives, (iv) communication and employee training on the methodology, and (v) strategic review meetings. Thus, it was created a corporate map that allows strategy management of the OC group, and strategy maps for each of its core businesses: distribution, generation and transmission of electricity. After this first cycle, some maps were unfolded in maps of support areas such as information technology, procurement and human resources.

Strategy maps have the four perspectives of the BSC methodology presented by Kaplan and Norton (1992, 1993, 1996): financial, learning and growth, internal processes and consumer. In each perspective, are set strategic goals of the business or corporation. Each strategic objective is linked to indicators that allow measuring the accomplishment of the proposed goals and initiatives, which are actions necessary to achieve the strategic objectives. In 2006, the process of BSC implementation focused on translating corporate strategy into operational terms, the business strategy maps have been updated and validated, corporate maps and strategic panels of support processes were built, each with its strategic objectives and performance indicators in order to fit the main indicator directly derived from MP. In 2007, efforts turned to the alignment around the strategy and definition of goals of all the businesses of OC until 2012, as well as initiatives that would allow the achievement of corporate strategy. The meetings on BSC analysis occur at different levels. At meetings of strategic analysis, the impacts of contribution panels of each business to the corporate map are discussed.A survey of the use of the BSC by OC focused on the business map DBU. At meetings of DBU contribution, each board discusses their contributions to business map. Through interviews with the persons in charge of strategic indicators linked to this map, the ability of the tool was analyzed to allow better management of organizational strategy of the business of electricity distribution, verifying the flow of activities that enable the achievement of this strategy, as well as the unfolding of responsibilities throughout the organization's hierarchy. It was noted that the BSC translates strategy into objectives, measures, targets and initiatives, with unfolding of corporate indicators at the supervisor, managerial and operational levels. The approach allows the visualization of the main business activities, avoiding more intuitive decisions and corroborates the findings of Nakamura et al. (2005) - who realized that strategic activities are implemented through functional strategies involving several areas of the value chain and contemplating the different variables in the decision-making process of the organization.

In OC this development can be a mathematical and causeand-effect process, in accordance to Nuintin (2007) who demonstrate that the BSC enables managers to identify the causes and effects of transactions and decisions taken to achieve the expected results. Strategy maps, translation components of the strategy, present key information to senior management to monitor the strategy execution. The corporate map is dismembered in the business maps such as the map of DBU. This map has several strategic goals that contribute to the achievement of corporate objectives. There are goals in all perspectives, ranging from reducing accidents and improving the quality of service, to improvement of the image and higher value for shareholders. As in the maps of all businesses, financial indicators measured by EBITDA and the EVA are on top of the map, and to be reached, require the achievement of the objectives of the basic perspectives. 
In the electricity sector, the regulator operates by determining a fair return on invested capital and establishing levels of service quality. A DBU management analyst explains that the tariff of electricity distribution is composed of a share of non-manageable costs (where purchase prices are passed on to the consumer) and a portion of manageable costs (which is the focus of management strategic costs of the organization). The costs considered by the National Agency form Electric Energy (ANEEL) and those paid in tariff are consistent with the organization of reference - which is a fictitious entity that aims to simulate the conditions that would face a potential entrant in the market, fulfilling the conditions set out in the concession contracts. Thus, $O C$ needs to keep its costs below the benchmark set by the organization, under penalty of not being recognized in tariff - a situation in which the organization would bear all costs without passing them on to their customers. This analyst points out that there are situations where the goals are composed of indicators with opposite behaviors that conflict with each other.

An example lies in the goal of operational efficiency which pretends to keep costs within the limits and at the same time to ensure good standards of quality. By defining the ideal goal for these indicators, the organization can track its progress on the path to achieve the proposed objective. It is worth saying that if the organization seeks a very low value for the indicator DEC (equivalent length of power supply interruption), it will increase their costs. Thus, even if the cost of regulatory limits of the reference organization is breached, it cannot be considered by ANEEL - which would undermine the $\mathrm{OC}$ benchmarks and objectives in the financial perspective. On the other hand, if $O C$ greatly reduces costs, expenses and investments, the regulatory level of quality would be compromised, subject to the imposition of penalties by the regulator - which also has a negative impact on financial goals, besides damaging the image of the organization. Thus, the balance between cost, quality and investment is essential to the achievement of market objectives and financial ones. The target markets and stakeholders are deeply influenced by the regulatory issue. In the financial and consumer perspectives, there is practically no action to be taken. The objectives associated with these perspectives are the result of lower perspectives, learning and growth and internal controls. The concept of reference organization, established by ANEEL, has enormous impact on the various goals. Besides being very associated with the goals of operational efficiency, this concept has a strong influence on the investment objectives, whose suitability should prudently consider the regulatory limits, since investments with costs considered very high by the regulatory agency may not be recognized for her.

The tariffs are revised every five years tariff and ANEEL determines the rate and adjustments for the next period. The planning director said that the time after tariff revision is critical for SI. In the review, the costs of OC are evaluated by the regulatory agency, establishing a new tariff. Since then, all the gains in operational efficiency add shareholder value by up to five years, for only in the next tariff review these costs will be reassessed by ANEEL. If there is a tariff reduction, as the one occurred in 2008, previous gains have already been realized. Thus, from the determination by $\mathrm{AN}$ EEL of the maximum rate charged by the concessionaire, the organization must act to maximize their gains. In general, electricity distributors are remunerated for their assets. The growth in scale without increasing assets brings gains for the organization, sharing a portion of these gains with consumers while increasing the assets can be fully paid. With financial planning linked to a guaranteed budget, there is a base that ensures the execution of part of the actions and strategic initiatives. The strategic map of DBU is unfolded into contribution panels by directors, superintendents and managers. The content of management panels is deployed in operational indicators. At DBU, each manager has a performance contract, which is the contribution of the management panel. The content of management panels is deployed in operational indicators. At DBU, each manager has a performance contract, which is the management contribution panel. This contract is made to meet the strategic objectives of the organization and it is not bound to managerial remuneration. A tool of great relevance to the process is the information system that stores and displays information from maps, indicators and initiatives. The components of the indicator can be manually inserted or extracted from a database with which the system has interface. The system is the channel through which the objectives and performance indicators are monitored and source of information for the review meetings on contribution.

To manage SI the organization uses licensed and internally developed software, the legacies. Currently, the corporate and business maps have their information stored and displayed via Business Warehouse. This is a report module of the information system used by the organization that enables reading from the database the Enterprise Resource Planning and that can be customized to automatically feed the BSC indicators. The DBU contribution panels have their data stored and displayed through the software management of contributions to strategy, developed internally by the OC.

The operational indicators set out in the software Indicators Consultation (BOOK), were also developed by the organization. According to the DBU operational managers, the use of the BSC model as management system of OC's strategy is fully aligned to the operational strategy, as foretold by Kaplan and Norton (1996). Information from MP, from 30 years, and five-year cycle of strategy management are grouped into maps, perspectives, objectives, measures, targets and initia- 
tives that unfold from the corporate to the operational level going through business managers and superintendents.

The triangulation of statements with documents shows that the implementation of the BSC in the organization helped profoundly the strategy execution outlined in organizational planning. The analysis of the statements of all levels shows that the BSC has enabled continuous monitoring of nonfinancial factors that support the organizational strategy, as indicators of human resources and internal processes. In that sense, it was observed to be important that the communication on the BSC reaches all levels and functions within the organization's hierarchy, as there are corporate strategic objectives that unfold in contribution panels reaching the operational level. So that operational staff understand the relationship between their work and organizational strategy it is important that the BSC model also be communicated to them.

The superintendent of strategic planning also clarifies that the OC meetings are held on operational management and maintenance, among others in DBU business, where performance indicators are presented and discussed. Similarly, employees are asked to analyze how they can contribute to the achievement of organizational strategy. The information provided by strategic maps and BSC contribution panels provide enough allowance to assist decision-making by the management body, in that it links the management performance to the performance required for the business, which is derived from the organization's strategy. Thus, the BSC facilitates understanding and compliance by managers of the strategies outlined by senior management of the organization.

\section{Conclusions}

The model for performance evaluation and control known as BSC came to collaborate with SI and continuous improvement of processes, enabling organizations to establish actions aligned to their strategy aiming to create value. BSC contributed to meet shareholder, employee and customer expectations, to the achievement of strategies and, still, to improvement in services, internal processes, learning and innovation. Such model can help to disseminate the strategic plans of an organization at all levels, aiming to guide people's actions towards improvement of present and future performance through its four different perspectives.

The research described in this article, analyzed BSC use as part of a MCS on SI in a large Brazilian MEC. Through case method, it was observed that BSC is an extremely important model by allowing, in fact, the follow-up of the performance of financial and nonfinancial factors contributing to the accomplishment of organizational strategic objectives. Such follow-up is part of a strategy management proposal based on the structured flow of meetings enabling greater alignment and focus, turning continuous the planning and control process. It was understood that BSC in OC functions as part of a MCS as it allows a structured strategic planning and timely adjustments through a system of strategic alerts that can be activated in case of necessity or opportunity. In OC, top administration is the focus and the main user of the model and through BSC operates any area of the company, aligning it to its purposes.

OC strategy execution occurs through the enlargement of the action area of the group in electric power and gas distribution businesses all over the Brazilian territory and through some international projects. Besides business expansion, the organization aims to add value to the shareholders and the community through an appealing dividend policy, social and environmental actions, increased business profitability, integrated risk management, improvement in operational effectiveness and, still, promotion of an agreeable workplace climate. Strategy maps were designed for its main businesses aiming to ease $\mathrm{SI}$ through the assessment of indicators - which allow to measure the extension of the goals proposed and the actions necessary to accomplish the short term and long term corporate objectives.

The OC's BSC translates strategy into objectives, indicators, targets and initiatives with the unfolding of corporate indicators at the supervision, managerial and operational levels. The model implementation process in OC focused on the translation of the corporate strategy into operational terms, being used the four perspectives proposed in BSC. Meanwhile, it was noted that there is a hierarchy among the performance indicators as the financial indicators are at the top of the map and in order to reach them, the organization needs to accomplish the objectives of the grassroots perspectives. As such, hierarchy was not the main focus of this research and to deepen those issues new studies are recommended aiming to the better understanding of such subject. In short, drawing from the analysis carried out, it was observed that (I) BSC enables the translation of the strategy adopted by the MEC into objectives and goals aligned to financial, learning and growth, improvement of internal processes and customer perspectives as proposed by the BSC model; (2) the model could be used as a MCS, providing improvement in the process of corporate $\mathrm{Sl}$ and its diffusion at the different levels of organization; and that (3), in OC, the performance evaluation through integration of qualitative and quantitative measures was an important mechanism in the implementation of such strategies. 


\section{References}

ANDREWS, K.R. (197I). The concept of corporate strategy. Irwin, New York.

ANTHONY, R.N., Govindarajan, V. (2004). Management Control Systems. McGraw-Hill, New York.

ATKINSON, A., Banker, R., Kaplan, R., Young, S. (200I). Management Accounting, 3rd edition. Prentice Hall, Upper Saddle River, NJ.

BRYANT, L., Jones, D.A.,Widener, S.K. (2004). Managing value creation within the firm: An examination of multiple performance measures. Journal of Management Accounting Research, $16(1),|07-| 3 \mid$.

CARVALHO, G. S., Tostes, F. P. (2007). A implantação do Balanced Scorecard em uma organização brasileira do setor petroquímico: um estudo de caso. In: Proceedings of the XIV Congresso Brasileiro de Custos - João Pessoa - PB.

CRAVENS, D.W., Lassk, F. G, Low, G. S., Marshall, G.W., MoncriefW. C. (2004). Formal and informal management control combinations in sales organizations: The impact on salesperson consequences. Journal of Business Research. 57 (3), 24I-248.

EISENHARDT, K. (1989). Building theories from case study research.Academy of Management Review, 14 (4), 500-532.

GEORGE, A., Bennett, G. (2005). Case studies and theory development in the social sciences. MIT Press, Cambridge, Massachussetts.

GOMES, J. S., Salas, J. A (1997). Controle de gestão: uma abordagem contextual e organizacional - Textos e casos. Atlas, São Paulo.

ITTNER, C., Larcker, D. (1998). Are nonfinancial measures leading indicators of financial performance? An analysis of customer satisfaction. Journal of Accounting Research, 36 (Supplement), I-35.

JICK, T. (1979). Mixing qualitative and quantitative methods: triangulation in action. Administrative Science Quarterly, 24 (4), 602- 610 .

JOHNSON, H. T., Kaplan, R. S. (1987). Relevance Lost: The Rise and Fall of Management Accounting. Harvard Business School Press, Boston.

JONES, A., Hubig, L. (2006). Balanced University Decision Support, Available: http://ssrn.com/abstract $=931633$.
JORDÃO, R.V. D. (2009). Mudanças no sistema de controle gerencial na Extrativa Metalquímica S.A.: uma experiência brasileira de aquisição. Dissertação. Mestrado em Ciências Contábeis. Universidade Federal de Minas Gerais, Belo Horizonte.

KAPLAN, R., Norton, D. (1992). The Balanced Scorecard Measures that drive Performance. Harvard Business Review, 69 (I), 7I-79.

KAPLAN, R., Norton, D. (1993). Putting the Balanced Scorecard to Work. Harvard Business Review, 7| (5), I34- I 47.

KAPLAN, R., Norton, D. (1996). Using the Balanced scorecard as a Strategic Management System, Harvard Business Review, 74 (I), 75-82.

LIPE, M., Salterio, S. (2002). A note on the judgmental effects of the Balanced Scorecard's information organization, Accounting Organizations and Society, 27 (6), 53I-540.

MALMI,T. (200I). Balanced Scorecards in Finnish companies: A research note. Management Accounting Research, 12 (2), 207-220.

MECKLENBURG (2013). Balanced Scorecard Helps Public Sector Follow its Vision Despite Political, Fiscal and Organizational Challenges, Available: http://www.bscdesigner.com/ balanced-scorecard-helps-public-sector-companies.htm

MENDES, D. P.. (2002). O balanced scorecard como instrumento de avaliação do nível de desempenho logístico em uma organização de prestação de serviços. Florianópolis: Dissertação (Mestrado em Engenharia de Produção), UFSC.

MONTGOMERY, C. A., M. E. Porter (Eds) (I99I). Strategy: Seeking and Securing Competitive Advantage. Harvard Business School Press, Boston.

MOORE, M. (2003). The Public Value Scorecard:A Rejoinder and an Alternative to "Strategic Performance Measurement and Management in Non-Profit Organizations" by Robert Kaplan, The Kennedy School of Government, Harvard University. Working Paper \#|8.

NAKAMURA, W.T., Mineta, R. K. N., Martin, D. M. L.. (2005). Estudo exploratório do uso do balanced scorecard como um sistema de medição de desempenho estratégico. In: Proceedings of the II Encontro de estudos em estratégia da ANPAD, XXII, 08 a 10 jun , Rio de Janeiro, Brazil. 
NAKAMURA, W., Mineta, R., Martin, D. (2005). Estudo exploratório do uso do balanced scorecard como um sistema de medição de desempenho estratégico. In Proceedings of the II Encontro de estudos em estratégia da ANPAD, 08 to 10 june, Rio de Janeiro, Brazil.

NISTOR, C. (2008). An empirical research about the possibility of implementing balanced scorecard in universities. In: Proceedings of the 3rd International Conference on Economics, Law and Management. Romania.

NORREKLIT, H. (2000). The balance on the Balanced Scorecard - a critical analysis of some its assumptions. Management Accounting Research, II (I), 65-22.

NORTON, D., Kaplan, R. (200I). Organização orientada para a estratégia, 9th ed., Campus, Rio de Janeiro.

NUINTIN, A. (2007). Avaliação de desempenho utilizando os preceitos do Balanced Scorecard: o caso de uma organização produtora da commodity café. In: Proceedings of the XIV Congresso Brasileiro de Custos - João Pessoa - PB, Brazil.

PITKÄNEN, H., Lukka, K. (20I0). Three dimensions of formal and informal feedback in management accounting. Management Accounting Research. 22 (2), I25- I 37.

PRAHALAD, C. K., Hamel, G. (I990). The core competence of the corporation. Harvard Business Review, 68 (3), 79-9I.

SIMÕES, A. M. D., Rodrigues, J.A. (20I I). O uso e os impactos do Balanced Scorecard na gestão das empresas. Revisão da literatura e oportunidades de investigação. Revista lberoamericana de Contabilidad de Gestión, VIII (18), Julio-Diciembre, I-24.

SMITH, R. (20I2). Building the Balanced Scorecard in Public Sector Organizations. Available on line at http://www. odgroup.com/articles/public-sector-balanced-scorecard/

YIN, R. (1984). Case study research: Design and methods. Beverly Hills, Sage Publishing. 